Georgia State University

ScholarWorks @ Georgia State University

1998

\title{
Chimpanzee (Pan troglodytes) Counting in a Computerized Testing Paradigm
}

\author{
Michael J. Beran \\ Georgia State University, mberan1@gsu.edu \\ Duane M. Rumbaugh \\ Georgia State University, rumbaugh@gsu.edu \\ E. Sue Savage-Rumbaugh
}

Follow this and additional works at: https://scholarworks.gsu.edu/lrc_facpub

Part of the Cognitive Psychology Commons

\section{Recommended Citation}

Beran, M. J., Rumbaugh, D. M., \& Savage-Rumbaugh, E. S. (1998). Chimpanzee (Pan troglodytes) counting in a computerized testing paradigm. The Psychological Record, 48(1), 3-20. Available at:

http://opensiuc.lib.siu.edu/tpr/vol48/iss1/1/

This Article is brought to you for free and open access by the Language Research Center at ScholarWorks @ Georgia State University. It has been accepted for inclusion in Language Research Center by an authorized administrator of ScholarWorks @ Georgia State University. For more information, please contact scholarworks@gsu.edu. 


\title{
CHIMPANZEE (PAN TROGLODYTES) COUNTING IN A COMPUTERIZED TESTING PARADIGM
}

\author{
MICHAEL J. BERAN, DUANE M. RUMBAUGH, and \\ E. SUE SAVAGE-RUMBAUGH \\ Language Research Center, Georgia State University
}

\begin{abstract}
Using computer-mediated joystick manipulation, the ability of a common chimpanzee (Pan troglodytes) to select arrays of items equal to a given target number was examined. A random dot condition was included in which all sequence cues were eliminated as a means to reach the target numbers 1 to 4 . The participant, Austin, had only the quantity of items already selected as a record of how high the count had progressed. Performance on the random dot trials was found to be significantly above chance and improvement over time was also statistically significant. Results of this experiment provide evidence that Austin behaved with a knowledge that the quantity of items selected was the objective of the task rather than adhering rigidly to any specific pattern of selection. The results indicate that Austin had the ability to discriminate the number of items needed to reach the target number and then select items individually to reach that target quantity.
\end{abstract}

The debate over the numerical abilities of animals revolves as much around issues of definition as it does around competence (for a review see Boysen \& Capaldi, 1993; Davis \& Perusse, 1988). Although different processes such as counting, subitization, and protocounting can be used to explain the way an organism deals with numerosities, this experiment was an examination of counting in a chimpanzee (Pan troglodytes) on a computerized task in which items were individually selected to reach a

Michael J. Beran, Department of Psychology and the Language Research Center, Georgia State University; Duane M. Rumbaugh, Departments of Psychology and Biology and the Language Research Center, Georgia State University; E. Sue Savage-Rumbaugh, Department of Biology and the Language Research Center, Georgia State University.

This research was supported by National Institutes of Health Grant NICHD - 06016 to the Language Research Center of Georgia State University.

We thank John Kelley and Dana Nummerdor for their assistance in conducting experimental sessions with Austin. We also thank Dana Nummerdor for her assistance in the coding of videotaped sessions and David A. Washburn and Daniel Rice for their comments on earlier versions of this paper.

Correspondence concerning this article should be addressed to either Michael $\mathrm{J}$. Beran or Duane M. Rumbaugh, Language Research Center, 3401 Panthersville Road, Decatur, Georgia 30034 USA. 
target number. This experiment was intended as a further investigation of the work with chimpanzee counting started by Rumbaugh, Hopkins, Washburn, and Savage-Rumbaugh (1989).

Gelman and Gallistel (1978) presented five principles that were necessary for counting to be taking place. The one-to-one principle implies a correspondence between the tags used to count and the items being counted such that each item in an array is tagged only once per count. These tags separate the items already counted from those yet to be counted. The stable-order principle states that the tags must be used in the same order and that the same tags must be used each count. The cardinal principle refers to the significance of the last tag applied to the array as the final total number of items in the array. An understanding of the cardinal principle implies that, at any point in counting the items, the last tag applied represents the total number of items counted to that point. The abstraction principle states that the preceding three principles can be applied to any array (physical or nonphysical entities). The order-irrelevance principle states that the order of enumeration is irrelevant to the final count as long as one-to-one correspondence and the stable-order principle were followed.

According to Gallistel and Gelman (1992), human infants have an innate sensitivity to quantity. Humans are born with an understanding of the counting principles (although this understanding is not functional to the extent that it is in an adult). If so, it is then logical to seek out similar capacities in other animals, and in particular our closest relative, the chimpanzee.

Previous research into the numerical abilities of animals has provided evidence of basic skills that are required for counting to take place. In one paradigm an animal must select either the larger, the smaller, or some specific number of items (a relative numerousness judgment). This ability to distinguish the relative numerousness of an array is an important step in reaching the potential to count and has been demonstrated in rats (Capaldi \& Miller, 1988; Davis \& Albert, 1986), squirrel monkeys (Terrell \& Thomas, 1990; Thomas, Fowlkes, \& Vickery, 1980), rhesus monkeys (Hicks, 1956), a raccoon (Davis, 1984), and common chimpanzees (Boysen, Berntson, Hannan, \& Cacioppo, 1996; Rumbaugh, Savage-Rumbaugh, \& Hegel, 1987).

Other research has focused on the naming of quantities through the matching of presented quantities to numerals. Ferster (1964) taught two chimpanzees to match each of seven three-digit binary numbers to presented arrays. Matsuzawa (1985) conducted similar studies with a chimpanzee, as did Pepperberg $(1987,1994)$ with an African grey parrot. Boysen (1993) reviewed similar findings from her numerical experiments with chimpanzees that provided evidence that animals were able to learn and appropriately apply numerical labels to arrays of differing sizes and compositions. This skill is necessary in counting as it shows an understanding of cardinality.

Another skill required for counting is ordinality. Ordinality is the 
understanding that there is a sequence to the tags that are applied and that the order of the tags is important for judgments of relative value. Washburn and Rumbaugh (1991) tested ordinality with rhesus macaques and found that the macaques were capable of ordinal judgments. Boysen, Berntson, Shreyer, and Quigley (1993) also investigated the processing of ordinality by chimpanzees and found similar evidence of this ability.

The picture that emerges is one in which animals have shown the capability to make numerical judgments of various kinds. Animals have shown a sensitivity to relative numerousness, ordinality, and the matching of numbers to quantities. However, counting also requires the ability to apply tags to an array when the counter is presented with a number to count (Thomas \& Lorden, 1993). Any animal that can count must apply tags and understand that the tags can be used as a record of the total number of items counted (the cardinal principle).

Rumbaugh et al. (1989) undertook an in-depth experiment to teach a chimpanzee (Lana) to count to three, then later to four. Through an elaborate sequence of computerized testing conditions, the researchers were first able to remove perceptual or spatial relations that could be confounded. In later steps Lana generalized her skills to new shapes and colors. In the final condition, Lana could respond (via a joystick-controlled cursor) to a target number by touching boxes at the lower portion of the screen without the benefit of any specific visual feedback or cumulative record of her intratrial counting. Only her memory provided a record of the number of boxes selected as each box disappeared when counted. Because the values of the target numbers and the array of materials with which to count changed randomly across trials, the authors concluded that Lana's performance entailed the processes of ordinality and cardinality and also entailed a very reasonable approximation of an enumerative act. Her accuracy in counting, however, decreased as the value of the target numbers increased.

An understanding of all the principles set forth by Gelman and Gallistel (1978) is necessary for any claim of counting ability. The current experiment uses a paradigm similar to that of Rumbaugh et al. (1989). This new paradigm required counting items through their selection from a larger array. The chimpanzee, Austin, would have to recognize a target number as a symbol of a specific quantity of items and then select individual items of a provided array that would equal that target number. Although Austin's task was similar to the task presented to Lana, Austin had experienced a different and less complicated numerical training history than that of Lana (Rumbaugh et al., 1989). This new paradigm should offer more clues into the counting ability of Pan troglodytes, the amount of training needed to produce that ability, and a comparative perspective on the definition of counting from the point of view of Gelman and Gallistel (1978). 
Method

\section{Participant}

The participant, Austin, was a captive-born, 21-year-old male chimpanzee (Pan troglodytes) housed at the Language Research Center of Georgia State University. Austin had an extensive history in language learning as well as other symbolic tasks (Menzel, Savage-Rumbaugh, \& Lawson, 1985; Savage-Rumbaugh, 1986; Savage-Rumbaugh \& Rumbaugh, 1978; Savage-Rumbaugh, Sevcik, \& Hopkins, 1988). Austin had been trained to use a joystick in previous experiments and was regularly tested on a variety of computerized cognitive tasks involving joystick manipulation.

\section{Apparatus}

Austin was housed with four other chimpanzees in a building consisting of four indoor cages (900 sq. feet total) and two outdoor play yards (1,050 sq. feet each), all of which were connected. He was separated for test sessions and worked at a joystick port in one of the indoor cages using a Commodore Amiga 2000HD computer and 10848 Video monitor (screen size $27.5 \mathrm{~cm}$ by $17.5 \mathrm{~cm}$ ) with an attached Kraft Systems standard joystick. The monitor was approximately 1 meter from Austin's face. Sessions from 7/18/95 to 10/08/95 were recorded with a Sony $8 \mathrm{~mm}$ video recorder.

\section{Design and Procedure}

A target number was placed on the right side of the computer screen above a line that bisected the screen horizontally. A cursor (approximately 6 $\mathrm{mm}$ in size) appeared in the center of the bisecting line at the beginning of each trial. A trial began when Austin used the joystick to move the cursor to the target numeral. When the numeral was contacted the trial began, and the cursor was returned to the center of the screen. At the same time, a quantity of items (either Arabic numerals, dots, or both) appeared in the bottom half of the screen. Austin had to move the cursor to one of these and stop for $1 / 2$ second to select that item. Only one item could be selected at a time. The cursor disappeared, and it then reappeared at the center of the line after each selection. Austin ended a trial by moving the cursor back up to the target Arabic numeral, but the program also stopped a trial automatically due to certain errors involving the selection of too many dots or an out-of-sequence number. In all conditions the number of items available at the bottom of the screen varied from trial to trial (range 1 to 11) with a quantity of items as large or larger than the target numeral. All trials were recorded by the program as either correct or incorrect. If a trial was incorrect a buzzer sounded and the error type was recorded (see the section on coding for types of errors). A correct trial resulted in a melodic tone and a food reward. A correction procedure repeated a trial until it was answered correctly. 
The experimenter was seated either behind or to the side of the computer and was not aware of the target number. The experimenter was present only for set-up of the program and the distribution of food reward after a correct trial. Austin was maintained on a regular diet throughout the experiment and generally worked for preferred foods such as fruits. Testing occurred throughout the week (including weekends) and often there were two sessions per day (one in the morning and one in the afternoon). The session duration was generally about 1 hour, although all sessions were dependent on Austin's willingness to work. All sessions that included random dot and quasirandom dot trials (explained below) were videotaped.

The items presented on a trial, the arrangement of these items on the bottom of the screen, and the outcome of touching an individual item depended on the specific condition in which a trial occurred. From $12 / 08 / 92$ to $10 / 08 / 95$ Austin participated in 8 different conditions (Table 1). For the purposes of this paper only the results of the final three

Table 1

\begin{tabular}{|c|c|c|c|c|c|c|}
\hline \multicolumn{7}{|c|}{ Training History } \\
\hline Condition & Dates of Testing & Target & Items & Placement & Top & \#Trials \\
\hline Condition 1 & $12 / 08 / 92$ to $4 / 22 / 93$ & 1 to 7 & Num & Random & Num & 5516 \\
\hline Condition 2 & $3 / 09 / 93$ to $5 / 16 / 93$ & 1 to 7 & Both & Random & Num & 2762 \\
\hline Conditions 1 and 2 & $5 / 19 / 93$ to $1 / 23 / 94$ & 1 to 7 & Both & Random & Num & 11247 \\
\hline Condition 3 & $1 / 24 / 94$ to $4 / 12 / 94$ & 1 to 7 & Num & Random & Dot & 2628 \\
\hline Condition 4 & $4 / 13 / 94$ to $7 / 22 / 94$ & 1 to 7 & Both & Random & Dot & 2437 \\
\hline Conditions 3 and 4 & $7 / 23 / 94$ to $1 / 08 / 95$ & 1 to 9 & Both & Random & Dot & 5440 \\
\hline Condition 5 & $4 / 12 / 95$ to $7 / 18 / 95$ & 1 to 8 & Both & Sequence & Dot & 267 \\
\hline Condition 6 & $1 / 10 / 95$ to $10 / 09 / 95$ & 1 to 9 & Num & Sequence & Dot & 6876 \\
\hline Condition 7 & $7 / 18 / 95$ to $10 / 09 / 95$ & 1 to 4 & Dots & Sequence & Dot & 7903 \\
\hline Condition 8 & $7 / 18 / 95$ to $10 / 09 / 95$ & 1 to 4 & Dots & Random & Dot & 4277 \\
\hline
\end{tabular}

Note. Target refers to the possible target numbers in that condition. Items refers to the type of items placed in the bottom half of the screen for selection on a trial in that condition. Placement refers to the appearance of items in the bottom of the screen (Random items can be placed anywhere whereas Sequence means that items are placed into their specific number positions as reported in the text). Top refers to the type of item placed in the top half of the screen when an item was selected from the bottom.

conditions are emphasized, but a brief overview of the first five conditions is provided to give background training information (see Figure 1 for some examples of the screen appearance for various conditions).

In the first of these training conditions, Austin learned the ordinal positions of the numbers 1 through 9 . In this condition, the Arabic numerals were randomly dispersed around the bottom of the screen, and Austin had to select them in the correct order. When contacted, the numbers were automatically removed and placed randomly on the top of the screen. In the second condition, dots rather than the numbers were placed on the top of the screen. In the third condition, a dot was presented in place of one of the numerals on the bottom of the screen and Austin had to select the dot in its appropriate place. In this condition 


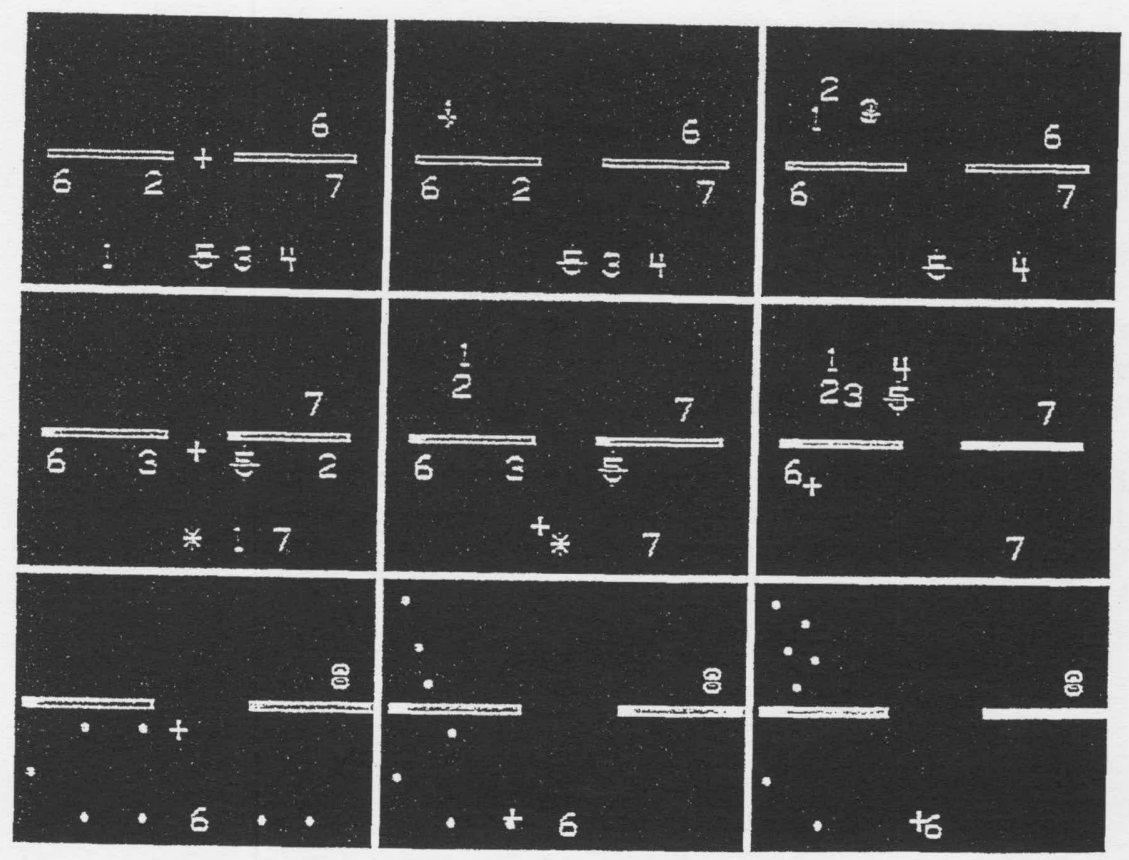

Figure 1. Condition 1 (top row), Condition 2 (middle row), and Condition 5 (bottom row). Note the cross that was placed over the Arabic numeral 5. It was intended as a means of preventing Austin from confusing the numbers 2 and 5.

the Arabic numerals were carried to the top of the screen but in the fourth condition only dots were carried. For Conditions 3 and 4, only one dot was presented per trial but Condition 5 included up to eight dots per trial.

The test phase of this experiment included Conditions 6 through 8 . In each of these conditions the numbers or dots placed on the bottom of the screen were in 1 of 11 possible positions. Position 1 was the position just under and to the left of the bisecting line. Positions 2-11 continued in a counter-clockwise direction with Position 11 being the position just under and to the right of the bisecting line. Whether dots or numerals appeared on a given trial depended on the condition (explained below), and the item carried to the top after a selection was the same as the items placed on the bottom (either dots or numerals). A single control session (of approximately 70 trials) had been run earlier in which the items placed at the top of the screen after each selection were removed from view during the trials, and performance was not affected. These carried items were included, in Conditions 7 and 8 , as a visual reminder to Austin of how many items had already been selected.

Condition 6 - Sequential-Number Trial. A sequential-number trial (see Figure 2, top left) involved the presentation of Arabic numerals in an orderly sequence around the bottom half of the screen. Austin had to 

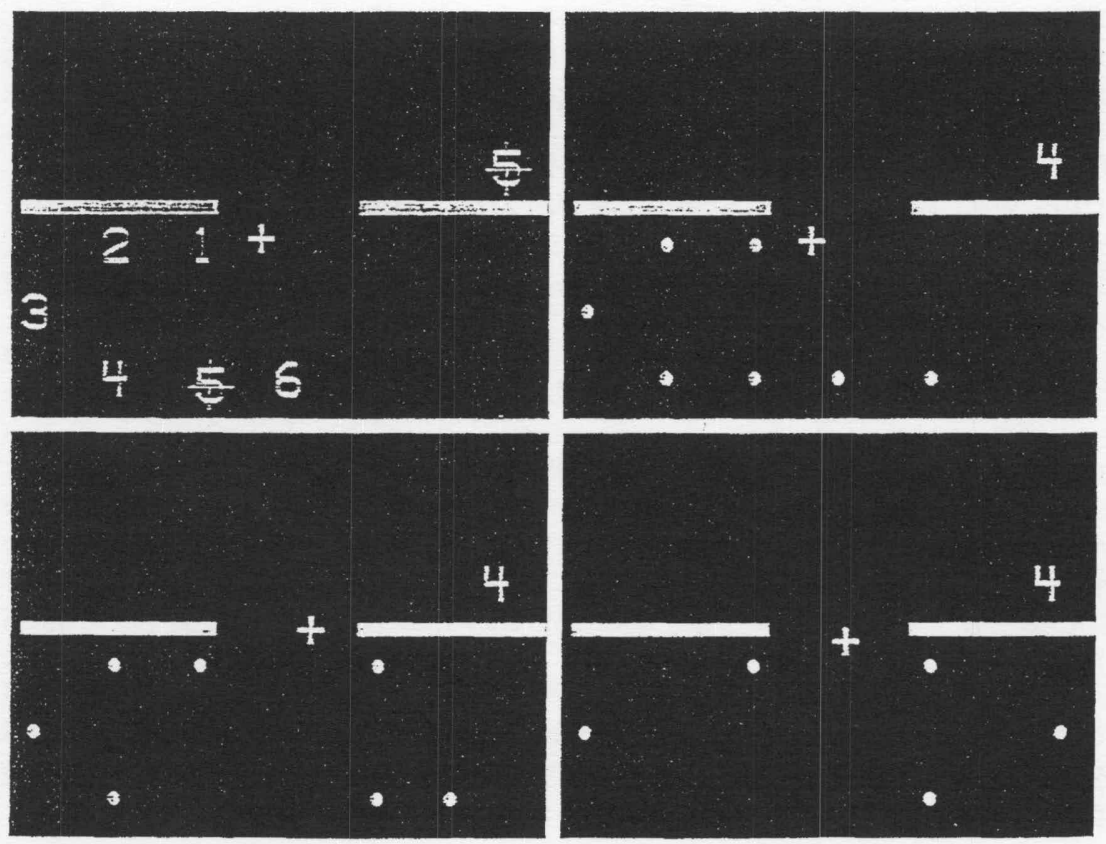

Figure 2. Condition 6 (top left), Condition 7 (top right), and Condition 8 (random dot bottom right, quasi-random dot bottom left).

select the numbers in the correct sequence until the target number was reached and then end the trial by returning to the target number. This condition was similar to the earliest one on which Austin was trained.

Condition 7 - Sequential-Dot Trial. In a sequential-dot trial (see Figure 2, top right) Austin selected dots placed sequentially around the bottom half of the screen to reach the target Arabic numeral. In this condition, the dots could be selected in any order. The dots were always arranged in a sequential pattern starting with Position 1 and going through the position containing the last dot.

Condition 8 - Random-Dot Trial. In a random-dot trial (see Figure 2, bottom right) dots were placed randomly throughout the 11 possible positions in the bottom half of the screen. The sequence of dots was broken up with positions containing no dots. Thus, in this condition Austin could not use the Conditions 6 and 7 sequential pattern that was available. In other words, when there were locations in the sequence with no dots, Austin could not correctly complete a trial by simply selecting dots until reaching the position where normally a trial of that target number was correctly completed. This was the first time that the random placement and the use of dots as counting items were employed together. However, on some trials it was possible for Austin to complete a trial correctly by selecting dots that were in a sequence at least to the 
point of the target number. This resulted when the computer, by chance, placed enough dots in sequence to reach the target number even though other positions with no dots broke up a complete sequence. These trials were designated as pseudo-random dot trials (see Figure 2, bottom left). The difference between pseudo-random dot trials and sequential dot trials was that pseudo-random dot trials had positions within the presented sequence that contained no dots, although those positions were greater than were required to reach the target number through sequential selection.

Austin has been tested on the target numbers 1 through 9 in the sequential number condition, the target numbers 1 through 5 in the sequential dot condition, and the target numbers 1 through 5 in the random dot condition. ${ }^{1}$ From $7 / 18 / 95$ until 10/08/95 all three conditions were presented in the same session with the ratio of trials per condition varying throughout the experiment. For the most recent sessions the ratio of trial type was 5 random dot trials, 4 sequential dot trials, and 1 sequential number trial per block of 10 trials (not including correction trials). Prior to $7 / 18 / 95$, Austin had seen random dot trials in only two sessions, and these sessions were not run for the collection of data but rather as a test of Austin's willingness to participant on the task when it was presented in this manner. Austin was helped by the experimenter on trials during these two sessions.

\section{Scoring}

All sessions including random dot trials were videotaped for coding. Each trial was coded for (a) type of trial (sequential number, sequential dot, or random dot), (b) correctness, (c) type of error (if incorrect), (d) specific dots or numerals selected by Austin, and (e) the order of item selection. There were three types of error. Out-of-sequence errors could occur only in the sequential number condition. These errors involved an incorrect selection sequence of Arabic numerals (e.g. selecting in order the numbers $1,2,3,5)$. Premature exit errors were those in which Austin ended a trial too early by moving the cursor back to the target number without having selected enough items from the array at the bottom of the screen. Late exit errors were those in which Austin selected one number or one dot greater than the target number.

\section{Results}

Austin's performance reached near perfection on the sequential number trials and his performance on the sequential dot trials also reached a high level of performance. For sequential number trials Austin was correct on 1,909 out of 1,923 trials across all target numbers $(>99 \%)$. Austin was also accurate for all target numbers in the sequential

${ }^{1}$ Although in apparent good health, Austin died suddenly on January 28,1996 . No cause of death was determined. He had just begun working with the target number 5 for both dot conditions when he died. Only one session was completed at the time of his death. 
dot condition (target number $1=97 \%$, target number $2=81 \%$, target number $3=84 \%$, and target number $4=84 \%$ ). However, these types of trials do not require a knowledge of the principles of counting to be answered correctly. Of primary interest in this experiment are the random dot trials.

The initial question was whether or not there was a difference within the random dot condition between those trials that were random and those that were quasi-random. Table 2 shows the difference between

Table 2

Performance on Random Dot and Pseudo-Random Dot Trials

\begin{tabular}{ccrccc}
\hline Target & \#QR \% Correct & N & R \% Correct & N & Total \% Correct \\
\hline 1 & $91.9 \%$ & 405 & $97.3 \%$ & 412 & $94.6 \%$ \\
2 & $84.7 \%$ & 196 & $73.5 \%$ & 649 & $76.1 \%$ \\
3 & $74.2 \%$ & 97 & $72.2 \%$ & 714 & $72.5 \%$ \\
4 & $70.0 \%$ & 50 & $59.3 \%$ & 772 & $59.7 \%$ \\
Total & $85.7 \%$ & 748 & $72.5 \%$ & 2547 & $76.7 \%$
\end{tabular}

Note. $\mathrm{QR}=$ quasi-random dot trials; $\mathrm{R}=$ random dot trials.

performance on the random dot and quasi-random dot trials for each target number. There was a significant overall difference between quasirandom and random dot trials $\left[X^{2}(1,4277)=45.1, p<.01\right]$. Because the only difference between the two types of trials had to do with the presentation of dots to be selected, we examined Austin's selection pattern. If the quasi-random trials were easier because of the afforded sequence of dots available, then Austin would have used this afforded sequential pattern. For the easier target numbers, 1 and 2, Austin used the available sequential pattern $62 \%$ and $52 \%$ of the time respectively. However, for the larger target numbers, 3 and 4, Austin never used the afforded sequential pattern (147 trials). A closer look at these quasirandom trials with target numbers 1 and 2 showed that Austin was more likely to follow the sequential pattern when there was no dot in the eleventh position. When a dot was in the eleventh position Austin was significantly more likely to select first the dot in Position 11 rather than the dot in Position $1,\left[X^{2}(1,285)=20.8, p<.01\right]$. By doing so, Austin avoided use of the afforded sequential pattern to reach the target number. This suggests that there was no advantage in having the dots presented in a manner that offered a sequential selection pattern to reach the target other than the close proximity of those dots to the cursor. The set-up of the screen was such that the dots that occupied Positions 1 and 11 were those dots most easily selected (see Figure 3 ) for time and distance. Figure 4 shows the percentage of times dots in each position were selected when available on random dot and quasi-random dot trials. As can be seen, Austin had clear preferences for those dots that were closest to the cursor when it was at the center of the screen (the dots in Positions 1, 2, 5, 6, 7, 10, and 11). Because the difference in performance levels between quasi-random and 


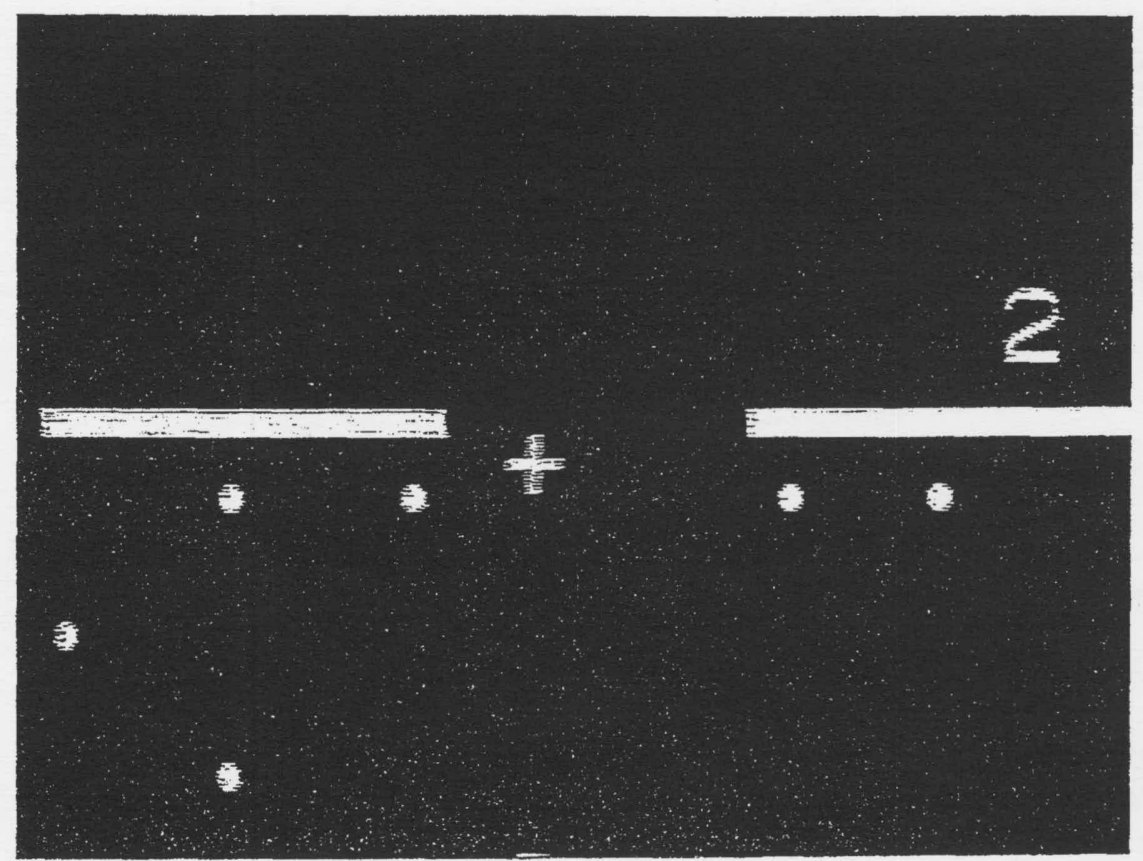

Figure 3. The proximity of the dots in certain positions to the cursor at the middle of the screen. Dots shown are in positions 1, 2, 3, 4, 10, and 11 (from top left counterclockwise).

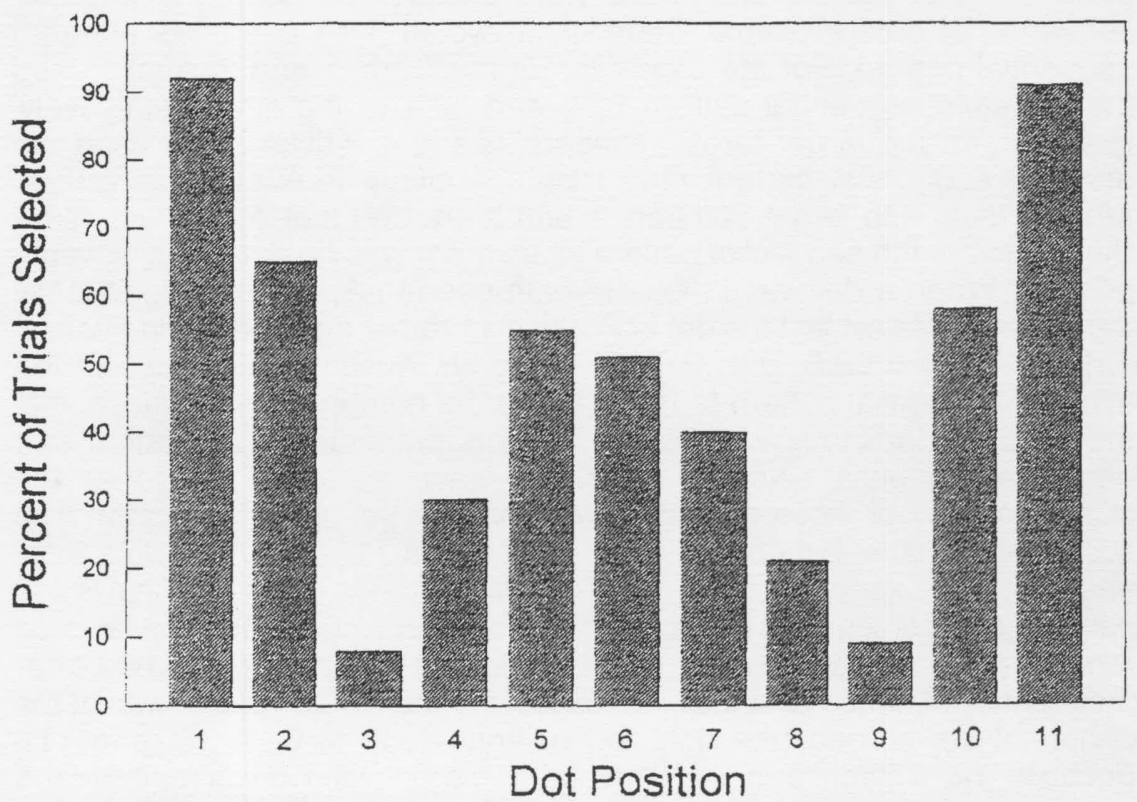

Figure 4. Percentage of trials in which dots in each position were selected when available. 
random dot trials did not appear to be the result of the afforded sequence but rather Austin's preference for selecting the nearest dots, the quasirandom and random dot trials were combined and are simply called random dot trials henceforth.

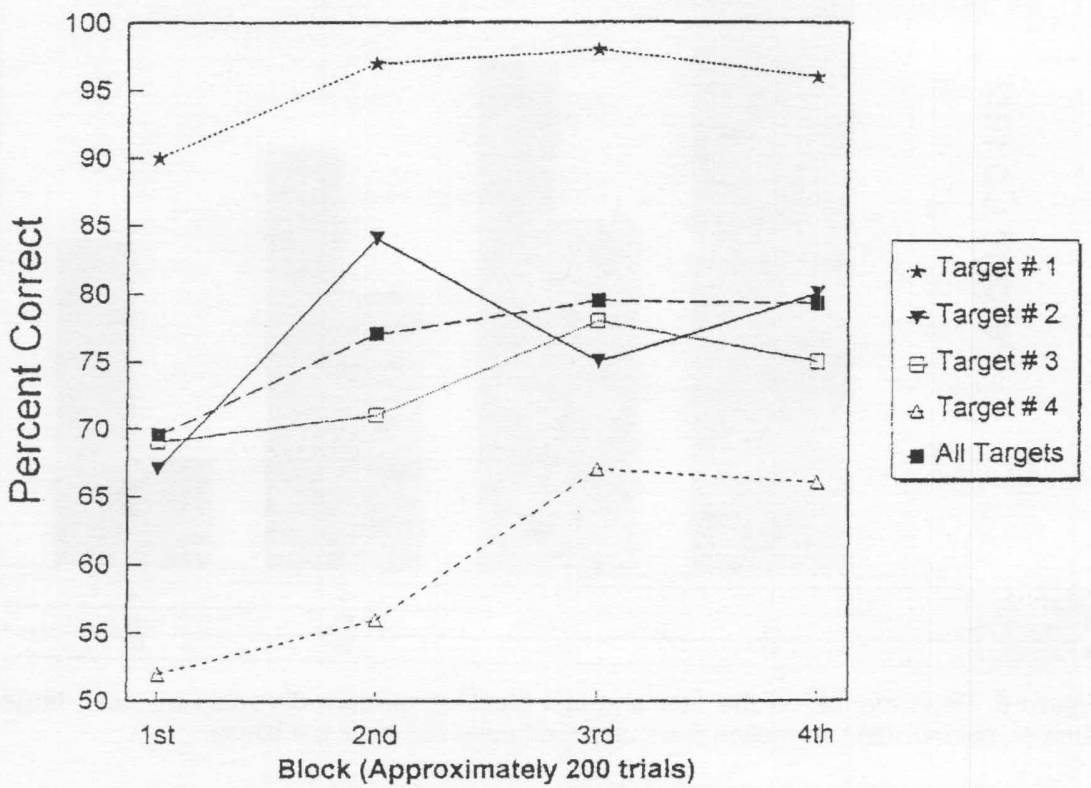

Figure 5. Performance in the random dot condition (not including correction trials) separated into four successive blocks of trials.

Figure 5 shows Austin's performance on random dot trials (not including correction trials). The trials were separated by target number into successive blocks of approximately 200 trials to show the progress made across the experimental period. Austin's performance overall on each target number was significantly greater than chance (all $X^{2}>$ 15.6, $p<.005)$. Chance was estimated to be 1 in 3 . Figure 6 presents Austin's performance on approximately the first 100 trials of each target number and the last 100 trials (not including correction trials). His performance on the last 100 trials was significantly greater than on the first 100 trials for target number $1\left[X^{2}(1,196)=5.19, p<.025\right]$, target number $2\left[X^{2}(1,221)=5.00, p<.05\right]$, and target number 4 $\left[X^{2}(1,206)=6.37, p<.025\right]$. Most important is the finding that Austin's performance was significantly greater than chance for the first 100 trials of each target number (not including correction trials) [target number $1\left[X^{2}(1,106)=60.4\right]$, target number $2\left[X^{2}(1,104)=60.2\right]$, target number $3\left[X^{2}(1,103)=41.1\right]$, and target number $4\left[X^{2}(1,105)=\right.$ $10.9]$, all $p<.005$ ]. Figure 7 presents a comparison of the performance of both Austin and Lana (Rumbaugh et al., 1989, Rumbaugh \& Washburn, 1993) for each target number in the final condition of their respective tasks. 


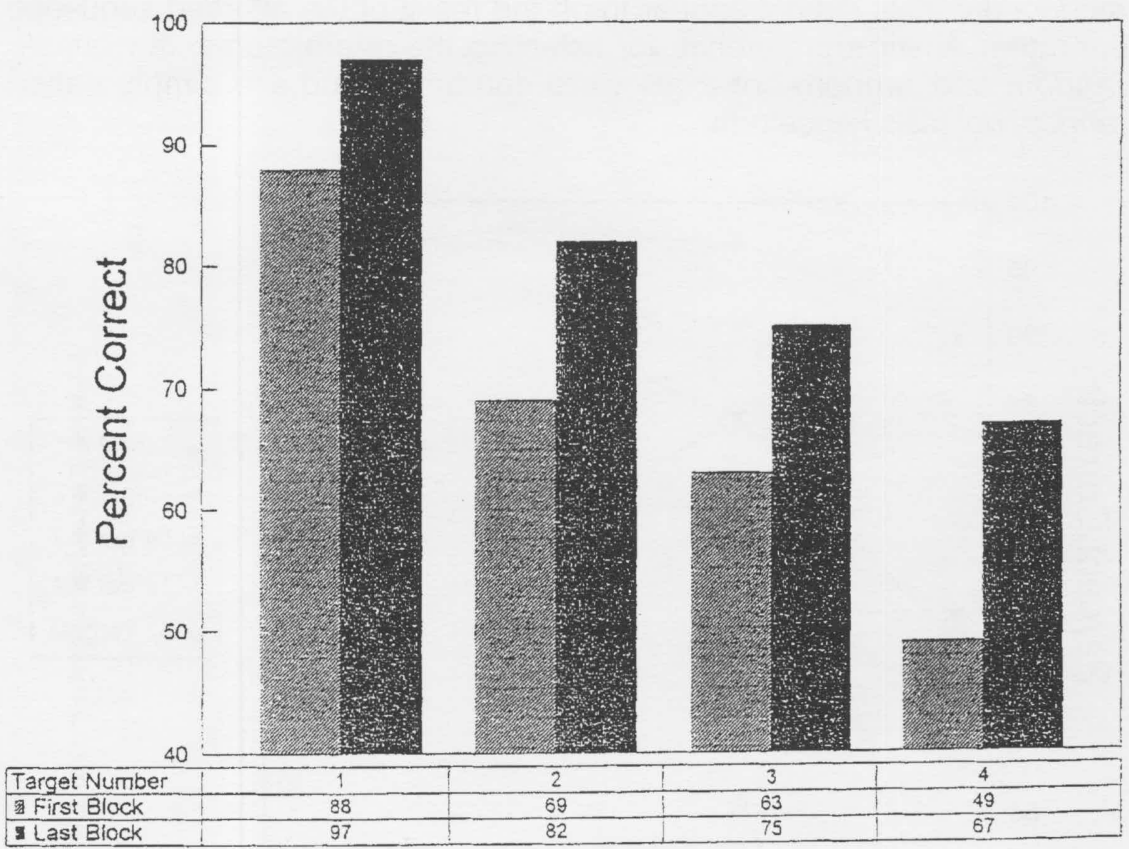

Figure 6. Performance on the first and last block of random dot trials for each target number, not including correction trials (approximately 100 trials per block).

Also of interest were those trials that Austin answered incorrectly. If Austin used a strategy reliant on quantitative selection then he should rarely have missed a trial more than once because of a knowledge that a different quantity of dots was needed on the correction trial. His performance did indicate this knowledge. He was correct on $94 \%$ of the correction trials with target number $1,81 \%$ with target number $2,83 \%$ with target number 3 , and $76 \%$ with target number 4 .

It was possible that Austin's performance on correction trials was achieved through a strategy of repeating what he had done on the incorrect trial and then correcting for the error without involving quantitative adjustment. This was, in part, possibly due to the program stopping any trial in which Austin went over the target number (a late exit error). All pairs of random dot trials that were incorrectly answered on the first trial and correctly answered on the second were examined. A pair of trials was scored as having a changed selection order if either of two conditions were met: (1) if Austin used at least one dot in the correction trial that was not used in the incorrect trial (not including dots selected after a premature exit error) or (2) if at least two dots were selected in a different order than in the incorrect trial. The total percentage of changed order of selection for all target numbers was $33 \%$. The percentage of change for each target number is given in Table 3 . 


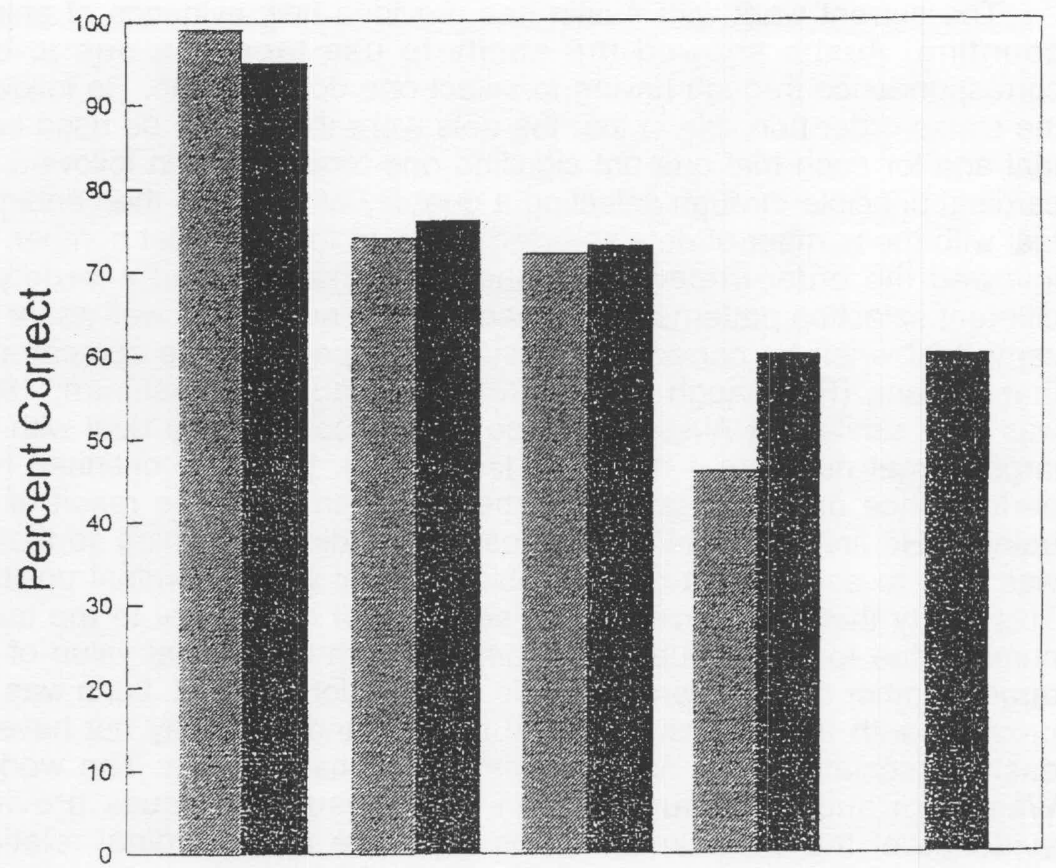

\begin{tabular}{|l|c|c|c|c|c|}
\hline Target Number & 1 & 2 & 3 & 4 & 5 \\
\hline Lana & 99 & 74 & 72 & 46 & Not Tested \\
\hline 1 Austin & 95 & 76 & 73 & 60 & 60 \\
\hline
\end{tabular}

Figure 7. Comparison of Lana's performance on NUMATH 19 and 20 and Austin's performance on random dot trials for each target number.

Table 3

Percentage of Changed Order of Selection for Each Target Number and Error Type

\begin{tabular}{crrrrr}
\hline Error Type & Premature Exit & $\mathrm{N}$ & Late Exit & $\mathrm{N}$ & Total \\
\hline Target \# & & & & & \\
1 & $0 \%$ & 5 & $14 \%$ & 35 & $13 \%$ \\
2 & $15 \%$ & 108 & $31 \%$ & 49 & $20 \%$ \\
3 & $37 \%$ & 113 & $42 \%$ & 55 & $39 \%$ \\
4 & $37 \%$ & 161 & $51 \%$ & 57 & $41 \%$ \\
\hline
\end{tabular}

\section{Discussion}

Previous work on animal numerical competence has provided a wealth of information on the numerical skills of animals. From the ability to discriminate two versus three to the ability to name an array of items on the basis of its numerosity, numerical research with animals has shown that they have the ability to deal with "number." However, the ability of an animal to truly count requires very specific knowledge (Gelman \& Gallistel, 1978). 
The current work with Austin has provided new evidence of animal counting. Austin showed the ability to use tags in a one-to-one correspondence through having to select one dot at a time. He followed the stable-order principle in that the dots were the tags to be used each trial and for each trial one dot signified one "count." Austin followed the cardinal principle through selecting a quantity of dots and then ending a trial with the number of dots selected standing for the target number. $\mathrm{He}$ followed the order-irrelevance principle in that he used a variety of different selection patterns for the same target number as well as for the same trial when he corrected a mistake. His performance compared to that of Lana (Rumbaugh et al., 1989; Rumbaugh \& Washburn, 1993) was very similar yet Austin was also able to competently deal with the larger target numbers 4 and, in a limited test, 5.2 This continued high performance on larger target numbers was probably the result of his training. He first had extensive exposure to ordinality training so that he was able to associate a given Arabic numeral with its ordinal position. This ability then transferred to the selection of dots equal to the target number due to a continued awareness of both the ordinal value of the target number and the cardinal value of each dot selected. Lana was not provided with this extensive ordinal training and thus may not have as easily associated each numeral with its ordinal position. The work of Washburn and Rumbaugh (1991) with rhesus macaques provides evidence of the importance of this exposure to the ordinal relations between numbers. The macaques were able to select correctly the highest number of a group of up to five numbers with no additional training. Austin directly benefitted from learning the ordinal positions of the numbers, and he was able to use this knowledge on the dot trials even though the task had changed considerably in that condition.

As much can be gained from looking at an animal's incorrect counting strategies as from looking at successful counting. Austin displayed an ability to count to a target number based solely on a discrimination of how many dots were necessary to reach that number. However, his performance was not perfect. We must, therefore, consider this inability to attain a perfect level of success (in particular with the target numbers 3 and 4). Specifically, we looked at the order of dot selection on correction trials. Because a trial was stopped as soon as Austin took one dot more than the target number called for (a late exit error), it was possible that he could just retrace his steps ending one dot selection earlier. When exiting too early, Austin could also just retrace his steps and then add one more dot to the quantity selected (Austin very rarely made an early exit error with more than one dot still needed). However, Austin did not always use these strategies. He frequently

2Although Austin was tested on only one session with the target number 5 before he died, he correctly answered 6 out of 11 trials with that novel target number ( 3 out of 5 in the random dot condition). Although there are not enough data to determine his proficiency with target number 5 , it appears that Austin would have quickly learned to select the appropriate number of dots when presented with that target number. 
changed his selection pattern while still correctly selecting the appropriate number of dots. Overall, Austin changed his pattern of selection on $33 \%$ of the correction trials.

More strikingly, Austin made a greater number of mistakes on the target numbers 3 and 4 and yet it was on these correction trials that he was most likely to change his pattern (and number) of dot selections. For the target number 3 , Austin changed the pattern of dot selection $39 \%$ of the time on correction trials. For the target number 4 , he changed the pattern of dot selection $41 \%$ of the time. With the realization that Austin maximized his efforts by taking those dots closest to the cursor as it reappears (Figures 3 and 4), one can see that changes greater than $30 \%$ are high because there were some dots that were rarely used unless necessary (Austin rarely selected the dots that were farthest away, those in positions 3 and 9). This suggests that Austin did not just learn to "repeat the pattern but take (or leave) another dot." Rather, it indicates that Austin changed his behavior based on the knowledge that he was incorrect due to the quantity selected. This seeming understanding led to the use of a correction strategy based on selecting a different quantity of dots on correction trials. It is also important to note that trials with the larger target numbers 3 and 4 generally took longer as they required more dot selections. This increased response period also increased the opportunity for non-task distractions within the laboratory to occur. Although these distractions would not have led to a large number of errors, the ease with which chimpanzees are distracted while working certainly must also be taken into account when addressing the number of errors that Austin made.

Austin has shown an ability to count a number of dots based only on the Arabic numeral presented to him. His performance was equal to that of Lana (Rumbaugh et al., 1989; Rumbaugh \& Washburn, 1993) but with a less complicated training history. Although in some conditions Austin could respond correctly by just selecting items to a certain point in the array for each target number, constantly changing patterns and numbers of available dots between trials of the same target number did not afford this opportunity in the random dot condition. Yet Austin still proved capable of correctly selecting the number of dots needed to reach the target number.

The paradigm presented in this experiment is one that lends itself to a new and more thorough examination of counting ability. It requires a determination of the number of items needed and then the selection of a quantity equal to that number. It requires the ability to apply the first three principles of counting as they have been defined by Gelman and Gallistel (1978). The current paradigm also allows the participant to "point" to each item with the cursor to facilitate its being added to the count. According to Gelman and Gallistel (1978), pointing coordinates the tagging and partitioning processes of the counting procedure. Boysen, Berntson, Shreyer, and Hannan (1995) found this behavior emerge in their work with counting and chimpanzees. Although the 
cursor that Austin used is different from an actual finger, the principle is the same. This paradigm is especially valuable as a carefully controlled means of continuing cross-species examinations of numerical skills in a way that allows for more uniform comparisons. The use of a computer here eliminates the possibility of experimenter cuing, that is otherwise a risk, and its applications can provide future insight into the nature of animal numerical competencies.

\section{References}

BOYSEN, S. T. (1993). Counting in chimpanzees: Nonhuman principles and emergent properties of number. In S. T. Boysen \& E. J. Capaldi (Eds.), The development of numerical competence: Animal and human models (pp. 39-60). Hillsdale, NJ: Erlbaum.

BOYSEN, S. T., BERNTSON, G. G., HANNAN, M. B., \& CACIOPPO, J. T. (1996). Quantity-based interference and symbolic representations in chimpanzee (Pan troglodytes). Journal of Experimental Psychology: Animal Behavior Processes, 22, 76-86.

BOYSEN, S. T., BERNTSON, G. G., SHREYER, T. A., \& HANNAN, M. B. (1995). Indicating acts during counting by a chimpanzee (Pan troglodytes). Journal of Comparative Psychology, 109, 47-51.

BOYSEN, S. T., BERNTSON, G. G., SHREYER, T. A., \& QUIGLEY, K. S. (1993). Processing of ordinality and transivity by chimpanzees (Pan troglodytes). Journal of Comparative Psychology, 107, 208-215.

BOYSEN, S. T., \& CAPALDI, E. J. (Eds.). (1993). The development of numerical competence: Animal and human models. Hillsdale, NJ: Erlbaum.

CAPALDI, E. J., \& MILLER, D. J. (1988). Counting in rats: Its functional significance and the independent cognitive processes that constitute it. Journal of Experimental Psychology: Animal Behavior Processes, 14, 3-17.

DAVIS, H. (1984). Discrimination of the number three by a raccoon. Animal Learning and Behavior, 12, 409-413.

DAVIS, H., \& ALBERT, M. (1986). Numerical discrimination by rats using sequential auditory stimuli. Animal Learning and Behavior, 14, 57-59.

DAVIS, H. A., \& PERUSSE, R. (1988). Numerical competence in animals: Definitional issues, current evidence, and a new research agenda. Behavioral and Brain Sciences, 11, 561-615.

FERSTER, C. B. (1964). Arithmetic behavior in chimpanzees. Scientific American, 210, 98-106.

GALLISTEL, C. R., \& GELMAN, R. (1992). Preverbal and verbal counting and computation. Cognition, 44, 43-74.

GELMAN, R., \& GALLISTEL, C. R. (1978). The child's understanding of number. Cambridge, MA: Harvard University Press.

HICKS, L. H. (1956). An analysis of number-concept formation in the rhesus monkey. Journal of Comparative and Physiological Psychology, 49, 212-218.

MATSUZAWA, T. (1985). Use of numbers by a chimpanzee. Nature, 315, 57-59.

MENZEL, E. W., SAVAGE-RUMBAUGH, E. S., \& LAWSON, J. (1985). Chimpanzee (Pan troglodytes) spatial problem solving with the use of mirrors and televised equivalents of mirrors. Journal of Comparative Psychology, 99, 211-217. 
PEPPERBERG, I. M. (1987). Evidence for conceptual quantitative abilities in the African Grey Parrot: Labeling of cardinal sets. Ethology, 75, 37-61.

PEPPERBERG, I. M. (1994). Numerical competence in an African grey parrot (Psittacus erithacus). Journal of Comparative Psychology, 108, 36-44.

RUMBAUGH, D. M., HOPKINS, W. D., WASHBURN, D. A., \& SAVAGERUMBAUGH, E. S. (1989). Lana chimpanzee learns to count by "Numath": A summary of a videotaped experimental report. The Psychological Record, 39, 459-470.

RUMBAUGH, D. M., SAVAGE-RUMBAUGH, E. S., \& HEGEL, M. T. (1987). Summation in the chimpanzee (Pan troglodytes). Journal of Experimental Psychology: Animal Behavior Processes, 13, 107-115.

RUMBAUGH, D. M., \& WASHBURN, D. A. (1993). Counting by chimpanzees and ordinality judgments by macaques in video-formatted tasks. In S. T. Boysen \& E. J. Capaldi (Eds.), The development of numerical competence: Animal and human models (pp. 87-106). Hillsdale, NJ: Erlbaum.

SAVAGE-RUMBAUGH, E. S. (1986). Ape language: From conditioned response to symbol. New York: Columbia University Press.

SAVAGE-RUMBAUGH, E. S., \& RUMBAUGH, D. M. (1978). Symbolization, language, and chimpanzees: A theoretical reevaluation based on initial language acquisition processes in four young Pan troglodytes. Brain and Language, 6, 265-300.

SAVAGE-RUMBAUGH, E. S., SEVCIK, R. A., \& HOPKINS, W. D. (1988). Symbolic cross-modal transfer in two species of chimpanzees. Child Development, 59, 617-625.

TERRELL, D. F., \& THOMAS, R. K. (1990). Number-related discrimination and summation by squirrel monkeys (Saimiri sciureus sciureus and $S$. boliviensus boliviensus) on the basis of the number of sides of polygons. Journal of Comparative Psychology, 104, 238-247.

THOMAS, R. K., FOWLKES, D., \& VICKERY, J. D. (1980). Conceptual numerousness judgments by squirrel monkeys. American Journal of Psychology, 93, 247-257.

THOMAS, R., K., \& LORDEN, R. B. (1993). In S. T. Boysen \& E. J. Capaldi (Eds.), The development of numerical competence: Animal and human models (pp. 127-147). Hillsdale, NJ: Erlbaum.

WASHBURN, D. A., \& RUMBAUGH, D. M. (1991). Ordinal judgments of numerical symbols by macaques (Macaca mulatta). Psychological Science, 2, 190-193. 
